\title{
Green Synthesis of Silver Nanoparticles Using Pelargonium Quercetorum Agnew and Their Therapeutic Properties
}

BERRAK DUMLUPINAR ALTINSOY ( $\sim$ aslimberrak@gmail.com )

Istanbul Gelisim Universitesi https://orcid.org/0000-0002-0898-3043

Gökçe Şeker Karatoprak

Erciyes Üniversitesi: Erciyes Universitesi

\section{Research Article}

Keywords: Pelargonium quercetorum, Geraniaceae, silver nanoparticle, antimicrobial, cytotoxicity

Posted Date: March 26th, 2021

DOI: https://doi.org/10.21203/rs.3.rs-343255/v1

License: (c) (i) This work is licensed under a Creative Commons Attribution 4.0 International License.

Read Full License 


\section{Abstract}

Aim

The synthesis of nanosilver particles (AgNPs) from Pelargonium quercetorum Agnew. (Geraniaceae) and evaluation of the antimicrobial and the cytotoxic potential of AgNPs.

Materials \& Methods

The synthesized AgNPs were evaluated for antimicrobial and anticancer efficacy using the minimum inhibition concentration method and MTT (3-(4,5-Dimethylthiazol-2-yl)-2,5-Diphenyltetrazolium bromide) assay.

Results

The AgNPs inhibited approximately $90 \%$ the growth of gram-positive Staphylococcus aureus and gramnegative Esherichia coli and yeast Candida albicans pathogens at a concentration of $500 \mu \mathrm{g} / \mathrm{mL}$. The synthesized AgNPs showed excellent toxicity in MCF-7 cells, and specifically, pq70 AgNP inhibited the growth of MCF-7 cells by $52 \%$ at a concentration of $3.125 \mu \mathrm{g} / \mathrm{mL}$.

Conclusion

It was determined that the AgNPs, which had been synthesized from extracts that contained a high phenolic composition, were smaller in size, and showed high anticancer and antimicrobial properties.

\section{Introduction}

Since the beginning of the 21 st century, nanosilver particles (AgNPs) have been used in almost every field, widely used in physical, biological, and pharmaceutical applications (Allsopp et al. 2007). Due to its antibacterial, antiviral, and antifungal properties, it is an excellent candidate for many purposes in medicine. However, it has been reported in the literature that these nanoparticles may have negative effects on people and the environment (Narayanan and Sakthivel 2010; Sintubin et al. 2012; Prabhu and Poulose 2012; Salmiati et al. 2017; Souza et al. 2019). Physical, chemical, and biological synthesis methods for AgNPs have been described in the literature (Vijay et al. 2014; Vijayaraghavan and Ashokkumar 2017). The use of hazardous chemicals that may cause potential environmental and biological risks in most of the physical and chemical methods used in the synthesis of AgNPs is the main factor in not selecting these methods (Prabhu and Poulose 2012). In addition, chemical synthesis methods can absorb certain toxic substances on the surface and prevent their medical use (Parashar et al. 2009). Biosynthesis of metal nanoparticles is a simpler and less harmful method than a chemical method. Since cheaper efficient usage of AgNPs is a subject that needs to be investigated, appropriate environmental and economic methods should be used for synthesizing these nanoparticles. The search for such a method has led to the need for biomimetic production of AgNPs. Therefore, biological methods using microorganisms and plants are an alternative method applicable for AgNP synthesis. 
The family Geraniaceae is represented in Turkey by 4 genera, comprising Biebersteina, Geranium, Erodium, and Pelargonium, and a total of 62 species. Two species of Pelargonium, the most important genus of this family, have been recorded in the vegetation of Turkey (Davis et al. 1988; Trun et al. 2006; Brendlera and Van Wyk 2008). Pelargonium quercetorum is one of these species and is generally found in Northern Iraq, although it also grows in Hakkari Province in Turkey. This plant, which thrives at high altitudes and humidity, is popular in the spring in the region and is known as Tolk or Tolik. P. quercetorum. It has been given importance by the local people and also has a commercial value in the region. In addition to using this plant for medicinal purposes, the local people also use it for food purposes (Uce and Tunçtürk 2014). The traditional use of $P$. quercetorum as an antiparasitic is known in the Kurdistan region of Iran (Taherpour et al. 2007). In Turkey, it is used to treat throat disorders and skin wounds, and its seeds and leaves are used to blast boils. It is also used for chronic headaches, neck pains, and migraines (Uce and Tunçtürk 2014).

The importance of the Pelargonium species has been documented with $P$. reniforme Curt. and $P$. sidoides DC., which are used as traditional medicines in South Africa and registered with the European Pharmacopoeia. To date, $11 \%$ ethanolic $P$. sidoides extract, EPs 7630 , has been successfully used in the treatment of respiratory infections (Kolodziej and Kiderlen 2007).

It may be possible to reduce the use of antibiotics by allowing bacteria to inhibit resistance mechanisms as a result of the physicochemical interaction of AgNPs and plant extracts. In addition, due to the rich phenolic content and strong activities of the Pelargonium species, AgNPs synthesized from this plant have also been considered to be highly cytotoxic to breast cancer (Ansari and Akhtar 2009; Duca et al. 2009; Halees et al. 2009). For this reason, the biosynthesis of AgNPs was reported for the first time herein using different extracts that were obtained directly from the P. quercetorum plant. The main objectives of this study were 1 ) the biosynthesis of AgNPs directly using extracts of $P$. quercetorum; 2 ) characterization of these AgNPs using zeta potential, scanning electron microscopy (SEM), and UV-vis to its assess quality, morphology, and dimensions; and 3) determination of the antimicrobial and anticancer activity of AgNPs.

\section{Materials And Methods}

\section{Plant material, chemicals, and reagents}

P. quercetorum was collected in May 2014 in Hakkari Province, Turkey, and a voucher specimen was deposited in the herbarium of Hacettepe University (HUB 30648). Silver nitrate $\left(\mathrm{AgNO}_{3}\right)$, ethanol, and methanol were obtained commercially from Sigma-Aldrich (St. Louis, MO, USA). Nutrient agar (NA), nutrient broth (NB), Sabouraud dextrose agar (SDA), and Sabouraud dextrose broth (SDB), for appropriate microorganism culturing, were obtained from Merck (Darmstadt, Germany). Dulbecco's modified eagle medium (DMEM, Sigma-Aldrich) was used for the cell culture.

\section{Preparation of the extracts}


First, the standardized extract of $P$. sidoides (EPs 7630) was prepared with $11 \%$ ethanol, and then the dried root parts of the plant were roughly powdered and extracted 3 times for $8 \mathrm{~h}$ at $37^{\circ} \mathrm{C}$ in a shaking water bath with the $11 \%$ ethanol (pq11) and $70 \%$ methanol (pq70). The obtained extracts were combined and concentrated in a rotavapor $\left(37-38^{\circ} \mathrm{C}\right)$ under vacuum. The aerial part of the vegetable material was extracted in the same way as the $70 \%$ methanol (pqh) and then concentrated in the rotavapor. All of the extracts were lyophilized and stored at $-20^{\circ} \mathrm{C}$ until analysis.

\section{Instrumentation and characterization}

Formation of the AgNPs was characterized using SEM, UV-Vis spectrometry, dynamic light scattering (DLS) and Zeta potential. SEM images were obtained using a ZEISS EVO LS10 SEM (Oberkochen, Germany) with a working voltage of $25 \mathrm{kV}$. The effective diameter and surface charge of AgNPs were measured using Zetasizer (Malvern Panalytical Ltd., Malvern, UK).

\section{Formation of AgNP}

For this, $1 \mathrm{mg} / \mathrm{mL}$ concentrations of pqhAgNP, pq11AgNP, and Pq70AgNP were prepared as stock solutions. The AgNPs were synthesized from the P. quercetorum extracts, according to the method of a previous study (Şeker Karatoprak et al. 2017).

\section{Preparation of bacterial strains}

Bacterial cultures comprising gram-negative: Escherichia coli American Type Culture Collection (ATCC) 25922, gram-positive: Staphylococcus aureus ATCC 25923, and yeast: Candida albicans ATCC 14053 were used for the microdilution method. The bacteria were grown in NA, while the yeast was grown in DSA. The bacterial suspensions equivalent to the density of $0.5 \mathrm{McF}$ arland (for bacteria $108 \mathrm{CFU} / \mathrm{mL}$, for yeast $106 \mathrm{CFU} / \mathrm{mL}$ ) were prepared by comparing the density standard, using a PhoenixSpec Nephelometer (Becton Dickinson, NJ, USA), of the fresh subcultures in broth.

\section{Minimum inhibitory concentration (MIC)}

Antibacterial activity of the AgNPs was tested using the microdilution technique of Clinical and Laboratory Standards Institute (CLSI 2012). The MIC values were determined for the antimicrobial activity method of Altinsoy (Altinsoy et al. 2019).

\section{Cell culture}

MCF-7 ATCC HTB 22 cells (human breast adenocarcinoma cell line) were obtained from the ATCC. For the MCF-7 cells, DMEM, inactivated fetal bovine serum, antibiotic mixture, and L-glutamine were used.

\section{Cell viability assay}

After the MCF-7 cells were developed under suitable conditions, they were seeded at a ratio of 10,000 cells per well into a 96-well microplate. The grown cells were incubated with various concentrations of 
AgNPs (3.125-100 $\mu \mathrm{g} / \mathrm{mL})$ for $24 \mathrm{~h}$. The cytotoxic properties of AgNPs were investigated using the using MTT method (Yücel et al. 2018). Finally, the absorbance was read using an ELISA Synergy HT microplate reader (BioTek, Winooski, VT, USA) at $570 \mathrm{~nm}$. The experiments were repeated in triplicate and results were given as the mean \pm SD.

\section{Statistical analysis}

The experimental data were shown as the mean \pm SD. Statistical analysis was performed using ANOVA. Statistical significance was accepted as $p<0.05$ using the Tukey pairwise comparison test.

\section{Results And Discussion}

\section{Synthesis and characterization of the AgNPs}

The SEM images of AgNPs formed using pq11, pqh, and pq70 are shown in Figures 1A, 1B, and 1C. While the pq11, pqh, and pq70 mediated AgNPs were all spherical, they exhibited different sizes and size distributions, comprising $\sim 47 \mathrm{~nm}$ for pq11AgNP, $\sim 96 \mathrm{~nm}$ for pqhAgNP, and $\sim 35 \mathrm{~nm}$ for pq70AgNP, respectively. The UV-vis spectrum of pq11AgNP, pqhAgNP, and pq70AgNP showed absorption peaks at $\sim 434, \sim 460$, and $\sim 417 \mathrm{~nm}$, respectively, which are all characteristic peaks of AgNPs (Figure 1D). DLS was used to measure the effective diameter and size distribution of pq11AgNP, pqhAgNP, and pq70AgNP, as shown in Figures $1 \mathrm{E}, 1 \mathrm{~F}$, and $1 \mathrm{G}$, respectively. The maximum density was found to be $43-68 \mathrm{~nm}$ for pq11AgNP, 78-190 nm for pqhAgNP, and 28-50 nm for pq70AgNP, respectively. The sizes of pq11AgNP $(112 \mathrm{~nm})$, pqhAgNP $(122 \mathrm{~nm})$, and pq70AgNP $(61 \mathrm{~nm})$ were effective diameters measured using DLS. As in the AgNPs synthesized from microorganisms in a previous study, the large dimensions can be attributed to the presence of plant phytochemicals adhering to the surface of the AgNPs and to the partial accumulation of the AgNPs.

Karatoprak et al. reported that while the total amount of flavonoids in $70 \%$ methanolic $P$. quercetorum extract was (pq70) $64.95 \pm 2.93 \mathrm{mgCA} / \mathrm{g}, 11 \%$ ethanol extract (pq11) was found as $46.63 \pm 1.93 \mathrm{mgCA} / \mathrm{g}$, and herba extract (pqh) was found as $30.89 \pm 3.58 \mathrm{mgCA} / \mathrm{g}$ (Karatoprak et al. 2018). It was assumed that during the pq70 formation, the presence of total phenolic, flavonoids, and flavonol contents may have had an effect, since these molecules tend to easily react with metal ions to form complexes, they can participate in the formation process of Ag Np to form small-sized nanoparticles.

\section{Antimicrobial activities of the pq11AgNPs, pq70AgNPs, and pqhAgNPs}

The antimicrobial effects of AgNPs against various microorganisms are widely used. Their size, morphology, surface charge, surface coating, and synthesis procedures have been reported to affect the antimicrobial performance of AgNPs (Pal et al. 2007; Zodrow et al. 2009; Lago et al. 2011; Vimbela et al. 2018; Altinsoy et al. 2019). Due to the various plant phytochemicals with antimicrobial effects, many plant extracts have widespread use as antimicrobial agents (Şeker Karatoprak et al. 2017; Eruygur et al. 2019). In addition, essential oils rich in terpenic composition have gained importance as effective 
antimicrobial agents against commercial bacterial strains that cause infections (Behbahani and Shahidi 2019). In the last decade, several studies have reported the biosynthesis of Ag nanoparticles obtained from plant extracts, microorganisms, and fungi, and green synthesized AgNPs are considered as good sources of antimicrobial molecules (Dogru et al. 2017). AgNPs obtained from some microorganisms have been efficiently used against a wide range of microorganisms (Altinsoy et al. 2018).

The antibacterial activities of the synthesized AgNPs at different concentrations (500-3.91 $\mu \mathrm{g} / \mathrm{mL}$ ) were tested against $E$. coli, S. aureus, and $C$. albicans. The percentage of inhibition was compared with a positive control (Meropenem and Fluconazole) and a negative control $\left(\mathrm{AgNO}_{3}\right)$. Antimicrobial activity results were detected using the microdilution method and the results are shown in Figure 2 and Table 1. According to the results, the AgNPs exhibited approximately $90 \%$ inhibition against the studied grampositive and gram-negative bacteria at a concentration of $500 \mu \mathrm{g} / \mathrm{mL}$. It can be understood from Figure 2 that AgNPs exhibited inhibition in a dose-dependent manner. The AgNPs demonstrated $70 \%$ antimicrobial activity against $C$. albicans at a concentration $500 \mu \mathrm{g} / \mathrm{mL}$. It was seen that the antimicrobial effect of pq70AgNP tended to be higher than those of pqhAgNP and pq11AgNP based on the microdilution test.

Table 1. IC50 $(\mu \mathrm{g} / \mathrm{mL})$ values of pq11 Ag NP, pq70Ag NP, and pqhAgNP against selected pathogens.

\begin{tabular}{|llll|}
\hline \multirow{2}{*}{ AgNPs } & & \multicolumn{2}{c|}{ Pathogens } \\
\cline { 2 - 4 } & E. coli & S. aureus & C. albicans \\
\hline Pq11AgNP & $124.72 \pm 1.95^{\star}$ & $110.72 \pm 3.90^{\mathrm{a}}$ & $155.47 \pm 3.92^{1}$ \\
\hline Pq70AgNP & $99.25 \pm 1.95^{\star \star}$ & $103.04 \pm 4.10^{\mathrm{a}}$ & $108.45 \pm 1.95^{2}$ \\
PqhAgNP & $140.56 \pm 3.90^{\star \star \star}$ & $117.71 \pm 1.95^{\mathrm{b}}$ & $161.38 \pm 5.93^{1}$ \\
Meropenem & $<3.91^{\star \star \star \star}$ & $<3.91^{\mathrm{c}}$ & - \\
\hline Fluconazole & - & - & $<3.91^{3}$ \\
\hline
\end{tabular}

Values given as the mean \pm SD are within the $\pm 95 \%$ confidence interval. The difference between $\left({ }^{*} \star^{* * *}\right)$, $(a-c)$, and $(1-3)$ is statistically significant. pq11: $11 \%$ ethanol root extract, pq70: $70 \%$ methanol root extract, pqh: $70 \%$ methanol herba extract.

It was determined that $125 \mu \mathrm{g} / \mathrm{mL}$ of concentrated pq11AgNP reduced the proliferation of $E$. coli, $S$. aureus, and $C$. albicans by $55 \%, 63 \%$, and $\sim 43 \%$, respectively. At the same concentration, Pq70AgNP and PqhAgNP caused a decrease in viability of $68 \%, \sim 73 \%$, and $\sim 58 \%$, and $58 \%, 60 \%$, and $30 \%$ for E. coli, $S$. aureus, and $C$. albicans, respectively. Similarly, 31.25 and $15.62 \mu \mathrm{g} / \mathrm{mL}$ of pq70AgNP, respectively, showed much effective inhibition on S. aureus ( $53 \%$ and $\sim 27 \%)$, and E. coli $(\sim 35 \%$ and $\sim 30 \%)$ when compared to C. albicans ( $27 \%$ and $\sim 20 \%$ ). 
When the IC50 $(\mu \mathrm{g} / \mathrm{mL})$ values of the pq11Ag NPs, pq70AgNPs, and pqhAgNPs on E. coli were examined, all of the nanoparticles were statistically different. No sample had the same significance as Meropenem. On $S$. aureus, while the pq11AgNPs and pq70AgNPs were statistically the same $(p>0.05)$, no sample could reach the activity of Meropenem. The results are summarized in Table 1.

The highest inhibition activity on $C$. albicans was found with the pq70AgNPs, while it was statistically different $(P<0.05)$ than that of the pqhAgNPs and pq11Ag NPs. Given the overall effect on all of the pathogens, it was clear that the pq70AgNPs had lower IC50 values.

The minimum inhibitory concentration (MIC) values of the pqhAgNPs and pq70AgNPs were determined as $7.81 \mu \mathrm{g} / \mathrm{mL}$ for $S$. aureus (Table 2). Overall, the activity showed by the Pq70AgNPs was significantly higher than that of the Pq11AgNPs. In a previous study, AgNPs synthesized from $P$. endlicherianum showed a higher inhibitory effect against gram-positive S. epidermidis (Şeker Karatoprak et al. 2017). The cell membrane interactions of $S$. aureus and AgNPs predicted a very strong interaction when compared to E. coli and $C$. albicans. S. aureus, a gram-positive bacterium, has a very thick cell wall due to proteoglycan layers, which may strengthen the interactions between $S$. aureus cells and AgNPs, where the cells are effectively and rapidly deactivated. In contrast to that, gram-negative $E$. coli has thin cell walls, which may weaken the interaction between, $E$. coli cells and the AgNPs.

Table 2. MIC values of the pq11AgNPs, pq70Ag NPs, and pqhAgNPs $(\mu \mathrm{g} / \mathrm{mL})$.

\begin{tabular}{|llll|}
\hline AgNPs & \multicolumn{3}{c|}{ Pathogens } \\
\cline { 2 - 4 } & E. coli & S. aureus & C. albicans \\
\hline Pq11AgNP & 15.62 & 15.62 & 31.25 \\
\hline Pq70AgNP & 7.81 & 7.81 & 15.62 \\
PqhAgNP & 15.62 & 7.81 & 15.62 \\
Meropenem & 3.91 & 3.91 & - \\
\hline Fluconazole & - & - & 3.91 \\
\hline
\end{tabular}

Values given as the mean \pm SD are within the $\pm 95 \%$ confidence interval. pq11: $11 \%$ ethanol root extract, pq70: 70\% methanol root extract, pqh: $70 \%$ methanol herba extract.

\section{Cytotoxicity of the AgNPs against the MCF-7 cell line}

Exposure of cells to AgNP can induce changes in the form of the cells, decrease cell viability, increase lactate dehydrogenase release, and ultimately result in cell apoptosis and necrosis (Zhang et al. 2014). According to the results of this study, the AgNPs, synthesized by using a plant extract, were determined to have anticancer potential against the breast cancer cell line MCF-7. The nanoparticles, pq11 AgNP, pq70AgNP, and pqhAgNP, at concentrations between 25 and $100 \mu \mathrm{g} / \mathrm{mL}$ were found to be statistically different from the control group $(P<0.001)$. At a concentration of $100 \mu \mathrm{g} / \mathrm{mL}, \mathrm{pq} 11 \mathrm{AgNP}$ and pq70AgNP 
showed $89.47 \%$ and $91.66 \%$ lethal activity against the MCF-7 cells, respectively. It was noticed that the cytotoxic effect of the pqhAgNPs was lower than that of the pq11AgNPs and pq70AgNPs. The Pq70AgNPs at a concentration of $3.125 \mu \mathrm{g} / \mathrm{mL}$ inhibited $52 \%$ of the MCF-7 cell growth. The cytotoxic effect against the MCF-7 cells is shown in Figure 3. The AgNPs, synthesized from various microorganisms, confirmed a cytotoxic effect on the MCF-7 breast cancer cell line, confirming that the nanoparticle with the smallest particle size had a higher inhibitory effect (Altinsoy et al. 2019).

\section{Conclusion}

It can be concluded that the $P$. quercetorum components function as both reducing and stabilizing agents for the synthesis of pq11, pqh, and pq70 AgNPs and induce AgNP formation with different size and size distributions. The synthesized AgNPs exhibited dramatically enhanced inhibitory properties against the pathogenic strains. In addition, these molecules had intrinsic anticancer properties and also showed promising toxicity against the MCF-7 cell line; hence, these results will shed light on studies regarding their use as potential antimicrobial and anticancer agents. Herein, the use of AgNPs synthesized in conjunction with physicochemical interactions of AgNP and plant phenolic compounds from $P$. quercetorum extracts offered a promising alternative to reduce the use of chemical agents in the treatment of infection and cancer. In future work, focus will be aimed at in vivo biological activity and toxicity studies.

Future Perspective: It is predicted that AgNps will be easier to procure when compared to the existing physical and chemical methods, and they will contribute to various industrial branches by providing high efficiency, better quality, long-term stability, and lower cost. Especially in the pharmaceutical field, it will be very important in the design of new drugs. In addition, production using biological methods instead of chemical methods, which cause considerable environmental pollution, may lead to significant environmental gains. It is our belief that using identified antimicrobial and anticancer molecules from medicinal plants as reducing and stabilizing tools will provide a one-step and cost-effective procedure for the synthesis of eco-friendly and size-controllable AgNPs, with large production capability and effective antimicrobial and anticancer properties.

\section{Summary Points}

The biosynthesis of AgNPs was presented herein for the first time using different extracts obtained directly from the $P$. quercetorum plant.

The green synthesis of AgNPs is environmentally friendly. They are able to target resistant bacteria and can lead to new options in combating microbial resistance. In this study, the potential of $P$. quercetorum extract-enhanced AgNPs for use as a new treatment method against infections caused by Escherichia coli, Staphylococcus aureus, and Candida albicans was investigated and determined.

The herbal AgNPs not only had antimicrobial activity, but also cytotoxic activity against the breast cancer cells. Additionally, these nanoparticles can be a potential source of antimicrobial agents in hospital 
infections.

\section{Abbreviations}

$\mathrm{AgNO}_{3:}$ Silver nitrate

AgNPs: Nanosilver particles

ATCC: American Type Culture Collection

CLSI: Clinical and Laboratory Standards Institute

DLS: Dynamic light scattering

DMEM: Dulbecco's modified eagle medium

MCF-7 ATCC HTB 22: Human breast adenocarcinoma cell line

MIC: Minimum inhibitory concentration

NA: Nutrient agar

NB: Nutrient broth

pq11: 11\% ethanol extract of Pelargonium quercetorium

pq70: 70\% methanol extract of Pelargonium quercetorium

pqh: $70 \%$ methanol extract of Pelargonium quercetorium Herba

SDA: Sabouraud dextrose agar

SDB: Sabouraud dextrose broth

SEM: Scanning electron microscopy

\section{Declarations}

Ethics approval and consent to participate

Not applicable

Consent for publication

Not applicable

Availability of data and materials 
Not applicable

\section{Competing interests}

The authors declare that there is no conflict of interest.

\section{Funding}

This research did not receive any specific grant from funding agencies in the public, commercial, or notfor-profit sectors

\section{Authors' contributions}

Berrak Dumlupınar: Investigation, methodology, writing- original draft, Gökçe Şeker Karatoprak: Investigation, methodology, writing-review \& editing.

\section{Acknowledgements}

Not applicable

\section{References}

Allsopp M, Walters A, Santillo D (2007) Nanotechnologies and nanomaterials in electrical and electronic goods: a review of uses and health concerns, Greenpeace Research Laboratories, London.

Altinsoy B, Bingöl Özakpınar Ö, Gürbüz B, Rayaman P, Öçsoy İ, Soyoğul Gürer Ü (2018) Green synthesis and characterization of silver nanoparticles using the fungus Aspergillus niger and their bioactive potential against pathogenic microorganisms and cancer cells. Lat Am J Pharm. 37 (5):979-986

Altinsoy B, Şeker Karatoprak G, Öçsoy i (2019) Extracellular directed Ag NPs formation and investigation of their antimicrobial and cytotoxic properties. Saudi Pharm J. 27(1):9-16 https://doi.org/10.1016/j.jsps.2018.07.013.

Ansari IA, Akhtar MS (2019) Current insights on the role of terpenoids as anticancer agents: A perspective on cancer prevention and treatment, in: M. Swamy, M. Akhtar, (Eds.), Natural Bio-active Compounds, Springer, Singapore.

Behbahani AB, Shahidi F(2019) Melissa officinalis essential oil: Chemical compositions, antioxidant potential, total phenolic content and antimicrobial activity. Nutr Food Sci Res. 6(1):17-25 http://nfsr.sbmu.ac.ir/article-1-300-en.html.

Brendlera T, Van Wyk BE (2008) A historical, scientific and commercial perspective on the medicinal use of Pelargonium sidoides (Geraniaceae). J Ethnopharmacol. 119:420-433.

https://doi.org/10.1016/j.jep.2008.07.037 
Clinical and Laboratory Standards Institute (CLSI). Performance standards for antimicrobial susceptibility testing: 21st informational supplement (M100-S22). Wayne, PA: CLSl; 2012.

Dal Lago V, de Oliveira LF, de Almeida Goncalves K, Kobarg J, Borba Cardoso M (2011) Size selective silver nanoparticles: future of biomedical devices with enhanced bactericidal properties. J Mater Chem. 21 (33):12267-12273 https://doi.org/10.1039/C1JM12297E

Davis PH, Mill RR, Kit T (1988) Pelargonium L'Hérit, in: Flora of Turkey and the East Aegean Islands, P.H. Davis, (Eds.), University Press, Edinburgh, 10:106.

De Souza TAJ, Souza LRR, Franchi LP (2019) Silver nanoparticles: An integrated view of green synthesis methods, transformation in the environment, and toxicity. Ecotoxicol Environ. Saf.171:691-700 https://doi.org/10.1016/j.ecoenv.2018.12.095.

Duca G, Aricu A, Kuchkova K, Secara E, Barba A, Dragalin I, Ungur N, Spengler G (2019) Synthesis, structural elucidation and biological evaluations of new guanidine-containing terpenoids as anticancer agents. Nat Prod Res. 33(21):3052-3056 https://doi.org/10.1080/14786419.2018.1516658.

E. Dogru E, A. Demirbas A, B. Altinsoy B, F. Duman F, Ocsoy I, (2017) Formation of Matricaria chamomillaextract-incorporated Ag nanoparticles and size-dependent enhanced antimicrobial property. J Photoc Photobio B. 174:78-83 https://doi.org/10.1016/j.jphotobiol.2017.07.024.

Eruygur N, Koçyiğit UM, Taslimi P, Ataş M, Tekin M, Gülçin I (2019) Screening the in vitro antioxidant, antimicrobial, anticholinesterase, antidiabetic activities of endemic Achillea cucullata (Asteraceae) ethanol extract. S Afr J Bot. 120:141-145 https://doi.org/10.1016/j.sajb.2018.04.001.

Halees RY, Talib WH, Issa RA (2019) Varthemia iphionoides and Pelargonium graveolens extracts as a treatment of breast cancer Implanted in diabetic mice. Pharmacogn Mag. 15(65):698-707 https://doi.org/10.4103/pm.pm_18_19

Karatoprak GŞ, Fırat M, Koşar M (2018) Pelargonium quercetorum Agnew. bitkisinin antioksidan aktivitesinin belirlenmesi. Mersin Ünv. Sağlık Bilimleri Derg. 11(2):174-183 https://doi.org/10.26559/mersinsbd.398926.

Kolodziej H, Kiderlen AF (2007) In vitro evaluation of antibacterial and immunomodulatory activities of Pelargonium reniforme, Pelargonium sidoides and the related herbal drug preparation EPs® 7630. Phytomed 14(1):18-26. https://doi.org/10.1016/j.phymed.2006.11.020.

Narayanan KB, Sakthivel N (2010) Biological synthesis of metal nanoparticles by microbes. Adv Colloid Interface Sci. 156(1):1-13 https://doi.org/10.1016/j.cis.2010.02.001.

Pal S, Tak YK, Song JM (2007) Does the antibacterial activity of silver nanoparticles depend on the shape of the nanoparticle? A study of the gram-negative bacterium Escherichia coli. Appl Environ Microbiol. 73 (6):1712-1720 https://doi.org/10.1128/AEM.02218-06 
Parashar UK, Saxena SP, Srivastava A (2009) Bioinspired synthesis of silver nanoparticles. Dig J Nanomat Biostruct. 4(1):159-166

Prabhu S, Poulose EK (2012) Silver nanoparticles: mechanism of antimicrobial action, synthesis, medical applications, and toxicity effects. Int Nano Lett. 2(1):1-10 https://doi.org/10.1186/2228-5326-2-32.

Salmiati AS, Salim MR, Kueh ABH, Hadibarata T, Nur H (2017) A review of silver nanoparticles: Research trends, global consumption, synthesis, properties, and future challenges. J Chin Chem Soc. 64:732-756 https://doi.org/10.1002/jccs.201700067.

Sintubin L, Verstraete W, Boon N (2012) Biologically produced nanosilver: current state and future perspectives. Biotechnol Bioeng. 109(10):2422-2436 https://doi.org/10.1002/bit.24570.

Şeker Karatoprak G, Aydın G, Altinsoy B, Altınkaynak C, Koşar M, Öçsoy i (2017) The Effect of Pelargonium endlicherianum Fenzl. root extracts on formation of nanoparticles and their antimicrobial activities. Enzyme Microb Technol. 97:21-26 https://doi.org/10.1016/j.enzmictec.2016.10.019.

Şeker Karatoprak G, İlgün S, M. Koşar M (2017) Phenolic composition, anti-ınflammatory, antioxidant, and antimicrobial activities of Alchemilla mollis (Buser) Rothm. Chem Biodiversity 14(9):e1700150. https://doi.org/10.1002/cbdv.201700150.

Taherpour AA, Maroofı H, Kheradmand K (2007) Chemical composition of the essential oil of Pelargonium quercetorum Agnew. of Iran. Nat Prod Res. 21(1):24-27 https://doi.org/10.1080/14786410601035084.

Trun W, Kiderlen AF, Kolodziej H (2006) Nitric oxide synthase and cytokines gene expression analyses in Leishmania-infected RAW 264.7 cells treated with an extract of Pelargonium sidoides (Eps 7630). Phytomed. 13(8):570-575 https://doi.org/10.1016/j.phymed.2005.07.004

Uce İ, Tunçtürk M (2014) Hakkâri'de doğal olarak yetişen ve yaygın olarak kullanılan bazı yabani bitkiler. Biyoloji Bilimleri Araştırma Derg. 7(2):21-25

Vijay Kumar PPN, Pammi SVN, Kollu P, Satyanarayana KVV, Shameem U (2014) Green synthesis and characterization of silver nanoparticles using Boerhaavia diffusa plant extract and their anti bacterial activity. Ind Crop Prod. 52:562-566 https://doi.org/10.1016/j.indcrop.2013.10.050.

Vijayaraghavan K, Ashokkumar T (2017) Plant-mediated biosynthesis of metallic nanoparticles: A review of literature, factors affecting synthesis, characterization techniques and applications. J Environ Chem Eng. 5(5):4866-4883 https://doi.org/10.1016/j.jece.2017.09.026.

Vimbela GV, Ngo SM, Fraze C, Yang L, Stout DA (2018) Antibacterial properties and toxicity from metallic nanomaterials. Int J Nanomedicine 12(2017):3941-3965. Correction in: Int. J. Nanomedicine 13(2018):6497 https://doi.org/10.2147/IJN.S134526 
Yücel Ç, Aktaş Y, Değim Z, Yılmaz Ş, Arsoy T, Altıntaş L, Çokçalışkan C, Sözmen M (2018) Effects of insulin and embryonic stem cells loaded PLGA nanoparticles on pancreatic Beta TC cells. Acta Pol Pharm. 75(6):1377-1389 https://doi.org/10.32383/appdr/87017.

Zhang T, Wang L, Chen Q, Chen C (2014) Cytotoxic potential of silver nanoparticles. Yonsei Med. J 55(2):283-291 https://doi.org/10.3349/ymj.2014.55.2.283.

Zodrow K, Brunet L, Mahendra S, Li D, Zhang A, Li Q, Alvarez PJJ (2009) Polysulfone ultrafiltration membranes Impregnated with silver nanoparticles show improved biofouling resistance and virüs removal. Water Res. 43(3):715-723 https://doi.org/10.1016/j.watres.2008.11.014.

\section{Figures}



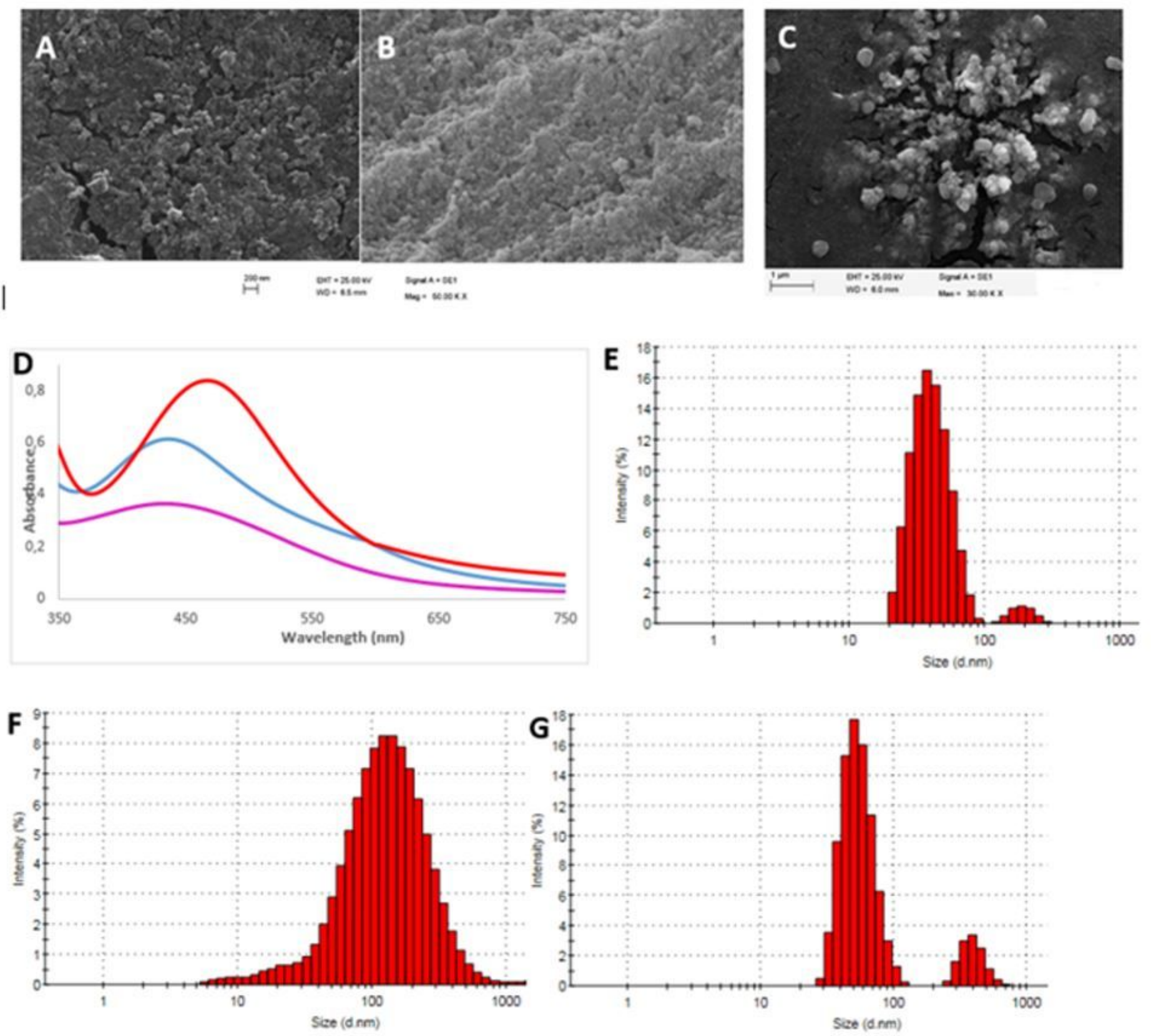

Figure 1

SEM images (A) pqhAgNP, (B) pq11AgNP, and (C) pq70AgNP. (D) UV-vis absorption spectra of the pqhAgNP (red line), pq11AgNP (purple line), and pq70AgNP (blue line) solutions. DLS results of $(E)$ pq11AgNP, (F) pqhAgNP, (G) pq70AgNP. 

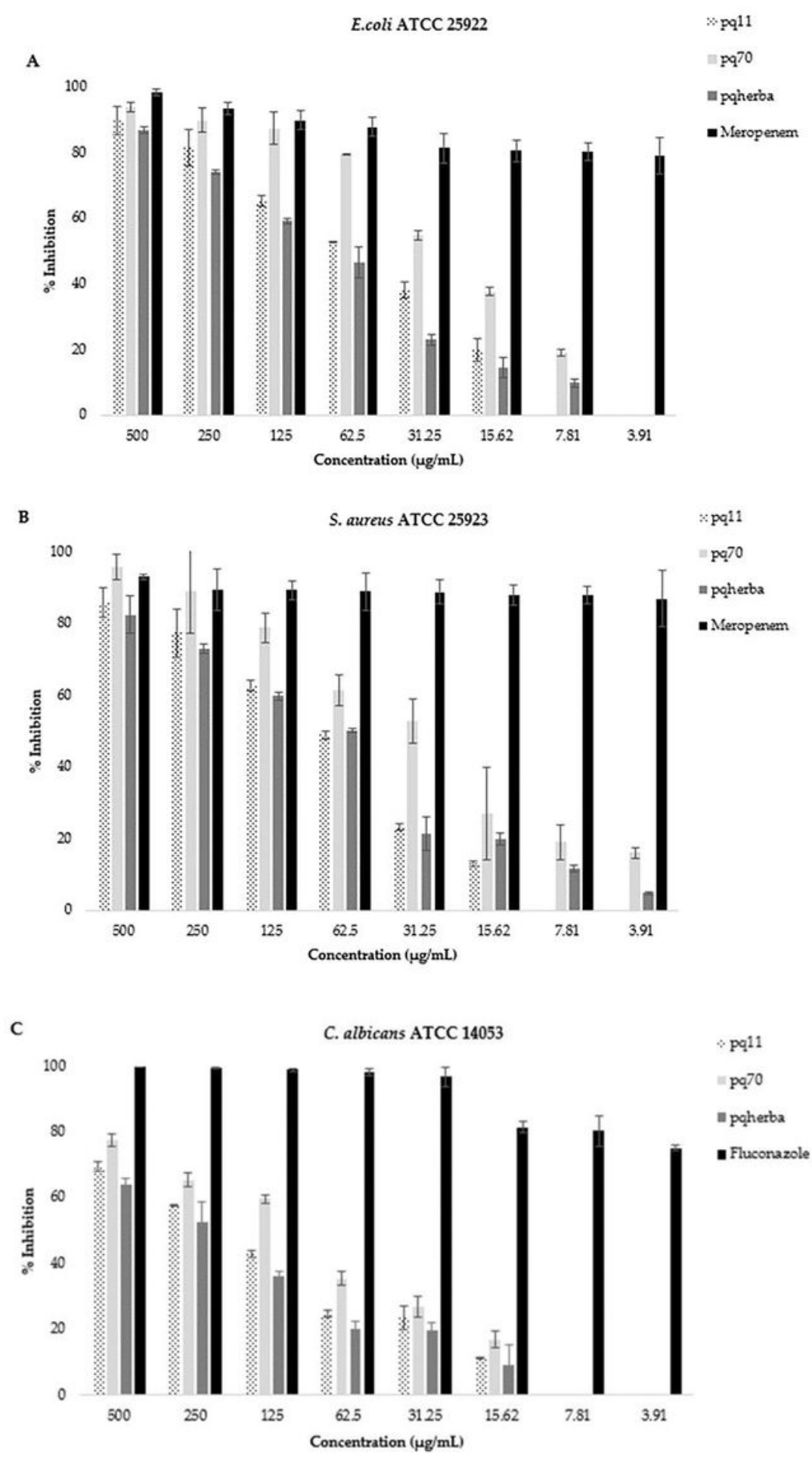

Figure 2

Inhibitory effect of the AgNPs with respective concentrations towards (A) E. coli, (B) S. aureus, and (C) C. albicans. Values given as the mean \pm SD are within the $\pm 95 \%$ confidence interval. pq11 AgNP: $11 \%$ ethanol root extract, pq70AgNP: 70\% methanol root extract, pqhAgNP: 70\% methanol herba extract. 


\section{MCF7}

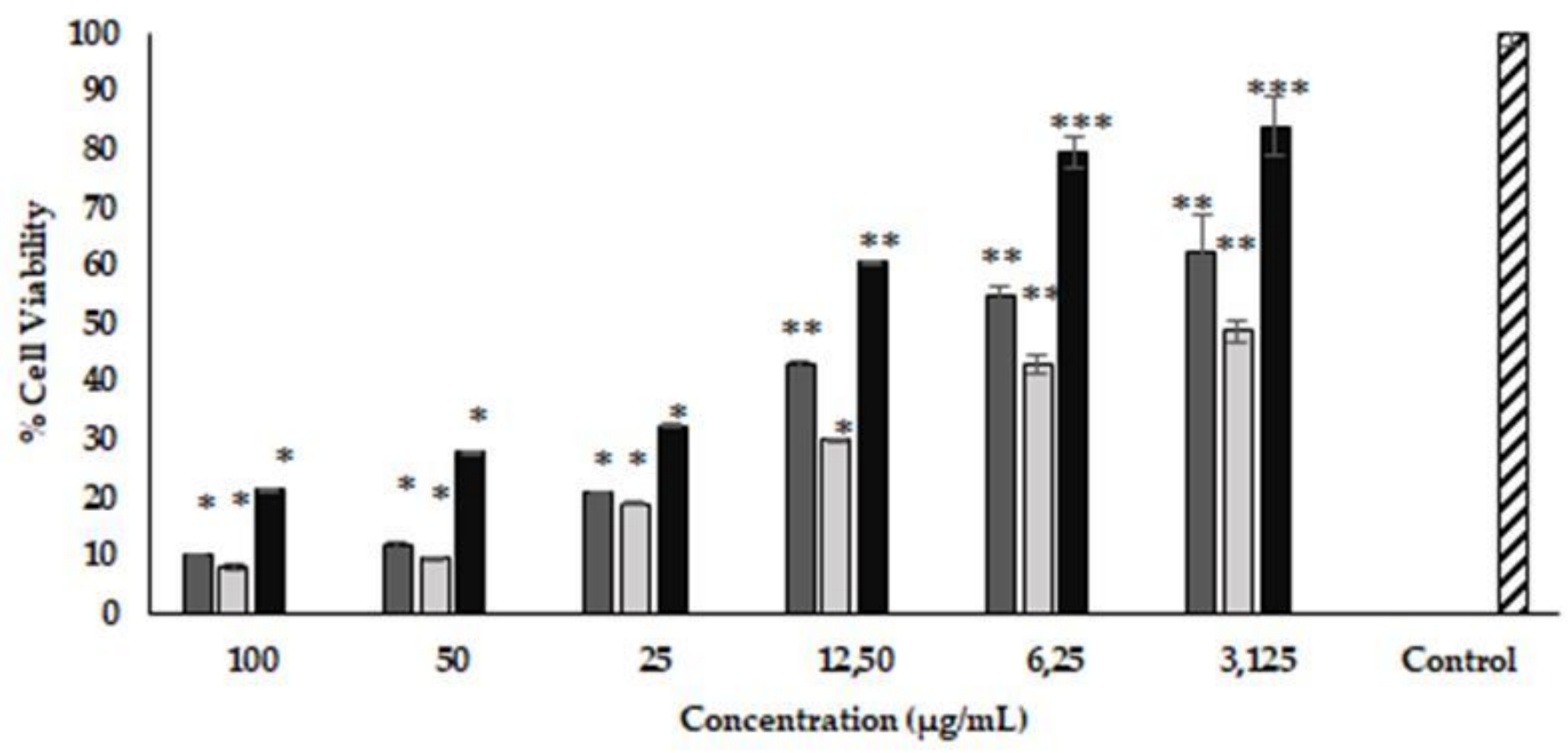

\section{口pq11AgNP $\square$ pq70AgNP QpqhAgNP [C Control}

\section{Figure 3}

Cytotoxicity of the AgNPs assessed by MTT reduction assay against the MCF-7 cell line. Data are expressed as mean \pm standard deviation, $n=3$. Significant differences are indicated as * $p<0.001$, ** $p<$ $0.01,{ }^{\star}{ }^{*}$ p < 0.05 . pq11AgNP: $11 \%$ ethanol root extract, pq70AgNP: $70 \%$ methanol root extract, pqhAgNP: $70 \%$ methanol herba extract.

\section{Supplementary Files}

This is a list of supplementary files associated with this preprint. Click to download.

- EditorialCertificate019101.pdf

- Futureperspective.docx

- gtaphicalabstract.pdf

- graphicsabstract.jpg 